\title{
The role of action planning and plan enactment for smoking cessation
}

\author{
Hein de Vries ${ }^{1 *}$, Sander M Eggers ${ }^{1}$ and Catherine Bolman²
}

\begin{abstract}
Background: Several studies have reemphasized the role of action planning. Yet, little attention has been paid to the role of plan enactment. This study assesses the determinants and the effects of action planning and plan enactment on smoking cessation.

Methods: One thousand and five participants completed questionnaires at baseline and at follow-ups after one and six months. Factors queried were part of the I-Change model. Descriptive analyses were used to assess which plans were enacted the most. Multivariate linear regression analyses were used to assess whether the intention to quit smoking predicted action planning and plan enactment, and to assess which factors would predict quitting behavior. Subsequently, both multivariate and univariate regression analyses were used to assess which particular action plans would be most effective in predicting quitting behavior. Similar analyses were performed among a subsample of smokers prepared to quit within one month.
\end{abstract}

Results: Smokers who intended to quit smoking within the next month had higher levels of action planning than those intending to quit within a year. Additional predictors of action planning were being older, being female, having relatively low levels of cigarette dependence, perceiving more positive and negative consequences of quitting, and having high self-efficacy toward quitting. Plan enactment was predicted by baseline intention to quit and levels of action planning. Regression analysis revealed that smoking cessation after six months was predicted by low levels of depression, having a non-smoking partner, the intention to quit within the next month, and plan enactment. Only $29 \%$ of the smokers who executed relatively few plans had quit smoking versus $59 \%$ of the smokers who executed many plans. The most effective preparatory plans for smoking cessation were removing all tobacco products from the house and choosing a specific date to quit.

Conclusion: Making preparatory plans to quit smoking is important because it also predicts plan enactment, which is predictive of smoking cessation. Not all action plans were found to be predictive of smoking cessation. The effects of planning were not very much different between the total sample and smokers prepared to quit within one month.

Keywords: Smoking cessation, Action planning, Preparatory planning, Plan enactment, Planned quit attempts

\section{Background}

Behavioral change strategies and pharmacotherapy are often recommended for smoking cessation because they have been found to be (cost)-effective [1]. Furthermore, a problem of behavior change in general, and thus also smoking cessation, is that people may indicate a willingness to change their behavior, but often fail to act on their intentions $[2,3]$. The intention-behavior gap is receiving increasing attention. One of the recommended

\footnotetext{
*Correspondence: Hein.devries@maastrichtuniversity.nl

${ }^{1}$ Care and Public Health Research Institute, Department of Health Promotion, Maastricht University, Maastricht, The Netherlands

Full list of author information is available at the end of the article
}

strategies to overcome this gap pertains to goal setting; persons undertake specific actions in order to carry out their intentions. Translating an intention into behavior requires self-regulative strategies that entail both cognitive and enactive acts, strategies that we refer to as action planning [4-8]. The latter has been found to be an effective way of bridging the intention-behavior gap for both health and patient education [8-17].

Several descriptions of action planning are available $[5,9,14,16-19]$. The commonality shared by the various descriptions is that action planning implies a sequence of behaviors used to translate an individual's intention 
into specific actions in order to achieve a desired behavior goal [20]. Action planning - as for instance outlined in the I-Change Model $[8,21,22]$ - can be described as the process of planning and executing specific actions that may help to adopt successfully and maintain a new health behavior. Action planning thus refers to the process by which a person aims to translate intentions into the goal behavior by setting various detailed plans action plans - to carry out and maintain this goal behavior [23]. Effective action planning is more likely to occur when persons are motivated to change $[5,17,24]$.

Goal setting refers to the end-goal that one wishes to accomplish $[25,26]$, and action planning refers to the choice of actions needed to achieve this goal and is comparable to setting proximal subgoals and using specific task strategies. Attainable action plans contribute to increased self-efficacy and task persistence, and will increase the likelihood of achieving the goal $[27,28]$. The beneficial effect of action planning is also acknowledged by Bagozzi $[4,29]$, who discusses the importance of preparatory actions in the process of translating an intention into behavior [12]. The importance of action plans is also acknowledged by the Transtheoretical model by identifying various processes of change by which individuals seek new information and find alternatives for their unhealthy behavior [30]. In addition, action planning has similarities with performance objectives as described by Bartholomew and colleagues [31], which pertain to the exact performances (actions) a person needs in order to achieve a final learning objective.

Action planning can entail at least two types of actions: preparatory actions and coping actions. Preparatory actions are actions that a person needs to undertake to prepare the behavior-change attempt [16,32-34]. Coping actions refer to actions needed to cope with difficult situations that may endanger the maintenance of the newly acquired health behavior $[13,14,17,35]$. Planning preparatory and coping actions may require a substantial amount of self-regulative effort. This contrasts with a particular type of action plan that is referred to as implementation intentions. Implementation intentions require less self-regulation, because their formation consists of actions that will (almost) automatically be executed when a specified cue occurs [5]. Although the application of implementation intentions can lead to significant effects [36], some studies found no effects aof implementation intention interventions on behavior [37-40]. One explanation for this lack of effects may lie in the fact that intention formation outside the laboratory consists of self-chosen plans [14], which are not necessarily effective plans. In sum, action planning, as referred to in the I-Change model, encompasses a range of different types of planning strategies that may differ in their level of self-regulation.
With regard to smoking cessation, several recommendations for action plans can be found in the literature as well as cessation guides, such as: planning to remove all tobacco products from the house; planning to ask guests not to smoke inside; planning to inform friends that you are about to quit; planning how to cope with withdrawal symptoms; planning to remain smoke free when feeling stressed, sad, or down; planning how to remain smoke free when seeing others smoke or ashtrays (for more examples, see $[41,42])$. Yet, little research has been done to test the efficacy of these plans in the process of smoking cessation. Moreover, some plans may be more effective for quitting, but may not necessarily be instrumental in achieving long-term change. Not all plans (or strategies as they are also known) may be effective. For instance, switching to "light" cigarettes has been found to be ineffective [43]. Hoving and colleagues [41] as well as Scholz and colleagues [44] found that action planning was positively related to successful quitting. Van Osch and colleagues [16] demonstrated that the addition of making coping plans in a Quit and Win campaign led to significantly higher quit rates. Hilberink and colleagues [42] found that Chronic Obstructive Pulmonary Disease (COPD) patients who were motivated to quit smoking within the next six months made significantly more action plans than those planning to quit smoking within the next year [42]. Yet, these studies did not assess which particular plans were predictive for smoking cessation.

Intuitively, the most important aspect of choosing particular action plans lies in their successful enactment [45]. However, one study revealed that, when given the opportunity, smokers actually used very few action plans in their smoking cessation attempt [22]. In order to be able to motivate smokers to choose effective plans, we need to know the efficacy of specific plans. Although goal setting implies both action planning and plan enactment $[6,12,26,31]$, little research is available describing the contributions of both planning and plan enactment.

This longitudinal study analyzed the role of action plans and their enactment in predicting attempts to quit and smoking cessation after one and six months. First, we describe which plans were chosen and which were enacted. Second, we examine which plans were related to attempts to quit and smoking cessation. Next, we test four hypotheses: Hypothesis 1, which is congruent with notions formulated by Sheeran, Webb, and Gollwitzer [24], states that individuals who intend to quit smoking within the next month will exhibit higher levels of planning than those intending to quit within a longer period of time. Hypothesis 2 states that higher levels of intention (Hypothesis 2a) and planning (Hypothesis $2 \mathrm{~b}$ ) will also lead to higher levels of plan enactment. Additionally, we postulate that higher levels of planning 
(Hypothesis 3) and plan enactment (Hypothesis 4) will be positively related to future smoking cessation behavior. Since planning is more likely to occur among smokers motivated to quit within a short period we will also assess whether the effects of specific plans will be different for smokers who are prepared to quit within one month.

\section{Method}

Ethical approval for this study was obtained from the Medical Ethics Committee of the Academic Hospital Maastricht and Maastricht University.

\section{Participant recruitment and study design}

For this study, a longitudinal design was used with a baseline assessment (T1) and follow-ups after one month (T2) and six months (T3). Smokers from the general population were recruited by advertisements via the website of the Dutch Smoking and Health Foundation. Smokers were asked to volunteer for a study on a new, computer-tailored, e-mail-delivered smoking cessation intervention. Participants were eligible for recruitment if they had been smokers for more than five years and were willing to quit within one year. They were informed that they had a 50\% chance of enrolling in the control group and would then receive non-tailored e-mail-delivered smoking cessation information. Participants had to register and approve participation and informed consent on the project's website. They were offered $€ 7.50$ to fill out all questionnaires. After registration, they received a login code and were asked to fill out the online baseline questionnaire. For the purpose of this study, we used the sample of the control group.

\section{Questionnaire}

The questionnaire used for all assessments was based on a version from an earlier study [46] and assessed demographic factors, smoking behavior factors, attitudes, social influence beliefs, self-efficacy, intention, and action planning.

Current quit attempt was assessed by asking if participants were carrying out a quit attempt at the specific time of measurement ( $0=$ No, $1=$ Yes $)$.

Smoking behavior at follow-up was assessed by asking whether participants were currently attempting to quit ( $0=$ No, $1=$ Yes $)$ and by asking 7 -day point prevalence abstinence $(0=$ Yes, I smoked during the past 7 days; $1=$ No, I did not smoke during the past 7 days [47]). At baseline, we also assessed the number of previous attempts at quitting, years as a smoker, and number of tobacco products consumed per day, to be used as covariates.

The demographics assessed included age, gender, and level of education ( $1=$ no education; primary or vocational school; 2 = secondary school; 3 = higher education, such as college/university).

Level of cigarette dependence was assessed by the 6-item Fagerström ([48]; $0=$ no dependence, $10=$ high dependence; Cronbach's alpha $=0.70$ ).

Depression was assessed by the 10-item CES-D questionnaire ([49]; $10=$ no indications of depression, $40=$ strong indications of depression; Cronbach's alpha $=0.86$ ).

Number of quit attempts was assessed by asking how many times the participant had tried to quit smoking previously (open ended question). Responses ranged from 1 to 16 times.

Intention to quit was assessed by asking when smokers intended to quit. Responses ranged from smokers intending to quit within a month (1) to smokers intending to quit within a year (0) [50].

Attitude was measured with two subscales. The pros of quitting consisted of the mean score of 9 statements on a 4-point scale $(0=$ No, certainly not; $4=$ Yes, certainly; Cronbach's alpha $=0.78)$. The cons of quitting were measured by nine statements on a 4-point scale $(0=$ No, certainly not; $4=$ Yes, certainly; Cronbach's alpha $=0.60$ ).

Social influence was assessed by two questions measuring the smoking behavior of the children and/or partner ( 1 = smoking, 0 = not smoking). These two questions were included separately in the analyses. Having no partner or no children was coded as 0 (not smoking).

Self-efficacy was measured by 16 questions on a 5-point scale ( $1=$ disagree, 5 = agree) asking participants to indicate how confident they were about overcoming specific barriers such as not smoking at parties, not smoking after dinner, etc. All scores were averaged to form a self-efficacy scale (Cronbach's alpha $=0.90)$.

Planning was assessed by asking respondents to rate on a 5 -point scale ( $1=$ definitely not, $5=$ definitely yes $)$ if they planned to carry out each of 12 different preparatory plans. The plans were selected from earlier studies $[22,42,46]$. All scores were averaged to form an actionplanning scale (Cronbach's alpha $=0.68$ ).

Plan enactment: At both follow-ups, participants were asked which of the 12 action plans they had executed. For each of the 12 plans, respondents could answer with Yes (1) or No (0). All scores were summed to form a plan enactment scale (Cronbach's alpha $=0.72$ ).

\section{Analysis}

All analyses were done using SPSS 19. Descriptive analyses were undertaken to describe the sample, and logistic regression was used to assess predictors of dropout. To describe the percentage of preparatory plans made in Table 1, scores were dichotomized as follows: "definitely yes" and "yes" into 1 vs. "not sure," "no," and "definitely no" into 0. Concerning Hypotheses 1 and 2, linear regression analysis was used to explore whether individuals who 
Table 1 Action plans and their enactment

\begin{tabular}{|c|c|c|c|c|c|c|}
\hline & \multicolumn{2}{|c|}{$\begin{array}{l}\text { Planned at baseline } \\
\text { (T1) }\end{array}$} & \multicolumn{2}{|c|}{$\begin{array}{l}\text { Executed after } 1 \text { month } \\
\text { (T2) }\end{array}$} & \multicolumn{2}{|c|}{$\begin{array}{c}\text { Executed after } 6 \text { months } \\
\text { (T3) }\end{array}$} \\
\hline & Total & PR & Total & PR & Total & PR \\
\hline To remove all tobacco products from your house & $72.5 \%(729)$ & $74.6 \%(586)$ & $39.1 \%(157)$ & $46.3 \%(145)$ & $42.7 \%(99)$ & $43.9 \%(82)$ \\
\hline To choose a specific quit date & $82.2 \%(826)$ & $87.2 \%(685)$ & $50.7 \%(204)$ & $56.5 \%(177)$ & $58.6 \%(136)$ & $59.4 \%(111)$ \\
\hline $\begin{array}{l}\text { To inform people in your environment that you } \\
\text { are about to quit smoking }\end{array}$ & $60.2 \%(605)$ & $64.0 \%(503)$ & $49.5 \%(199)$ & $53.4 \%(167)$ & $51.7 \%(120)$ & $50.3 \%(94)$ \\
\hline To do something different when you feel like smoking & $76.4 \%(768)$ & $76.3 \%(600)$ & $44.8 \%(180)$ & $48.6 \%(152)$ & $53.4 \%(124)$ & $54.5 \%(102)$ \\
\hline $\begin{array}{l}\text { To think about how you can prevent weight increase } \\
\text { after you have quit smoking }\end{array}$ & $73.8 \%(742)$ & $73.9 \%(581)$ & $41.8 \%(168)$ & $45.4 \%(142)$ & $46.6 \%(108)$ & $49.7 \%(93)$ \\
\hline To remove all ashtrays from the house & $43.0 \%(432)$ & $45.2 \%(355)$ & $21.4 \%(86)$ & $25.2 \%(79)$ & $25.0 \%(58)$ & $25.7 \%(48)$ \\
\hline To search for certain aids to help you quit smoking & $45.1 \%(454)$ & $42.4 \%(333)$ & $32.8 \%(132)$ & $35.1 \%(110)$ & $38.4 \%(89)$ & $41.2 \%(77)$ \\
\hline To break your habit of smoking at specific times and places & $85.8 \%(863)$ & $86.1 \%(677)$ & $44.3 \%(178)$ & $46.6 \%(146)$ & $49.6 \%(115)$ & $51.3 \%(96)$ \\
\hline To read information about how to quit successfully & $89.4 \%(898)$ & $90.5 \%(711)$ & $68.4 \%(275)$ & $70.6 \%(221)$ & $62.9 \%(146)$ & $63.6 \%(119)$ \\
\hline $\begin{array}{l}\text { To think about how to cope with difficult situations } \\
\text { before your quit attempt }\end{array}$ & $74.6 \%(750)$ & $75.7 \%(595)$ & $33.6 \%(135)$ & $34.5 \%(108)$ & $39.2 \%(91)$ & $38.5 \%(72)$ \\
\hline $\begin{array}{l}\text { To make non-smoking agreements with the individuals } \\
\text { living with you }\end{array}$ & $50.4 \%(507)$ & $51.0 \%(401)$ & $18.7 \%(75)$ & $19.5 \%(61)$ & $22.8 \%(53)$ & $23.5 \%(44)$ \\
\hline To find a buddy so you can quit together & $30.3 \%(305)$ & $31.4 \%(247)$ & $20.9 \%(84)$ & $21.7 \%(68)$ & $19.4 \%(45)$ & $20.9 \%(39)$ \\
\hline
\end{tabular}

intended to quit within the next month would exhibit higher levels of action planning at baseline and whether they would execute more action plans at follow-up (both normally distributed). To test additional explained variance and to add covariates, the enter method was used for all models. For Hypotheses 3 and 4, logistic regression analysis was used to explore if the levels of action planning and plan enactment were associated with smoking cessation. We used the test of joint significance [51] to asses if, and to what extent, the effect of action planning was mediated by plan enactment. Furthermore, age, education, gender, previous attempts to quit, level of cigarette dependence, level of depression, attitude, social influence, and self-efficacy were added to all models as covariates.

\section{Results}

\section{Sample characteristics}

In total, 1,005 participants filled out the online questionnaire at baseline. Mean age was 38.8 years $(S D=11.6)$; $68 \%$ were women. Participants smoked 19.8 cigarettes per day $(S D=8.6)$, had a smoking history of 21.3 years $(S D=11.4)$, and had made 3.8 previous attempts to quit $(S D=5.1)$. Mean cigarette dependence as measured by the Fagerström questionnaire was $4.9(S D=2.5)$. After one month, 221 participants (55\% of the complete cases) reported to be currently executing a quit attempt. After six months, 114 participants (49\% of the complete cases) reported to be executing a quit attempt. Similarly, complete case analysis indicated that 124 participants had quit smoking (measured by 7 -day point prevalence) after one month (34\%) and 97 participants after six months (41\%). When participants who were lost to follow-up are treated as smokers these percentages drop to $12 \%$ and $10 \%$, respectively.

The sample prepared to quit within a month consisted of 786 participants, aged 38.7 years $(S D=11.4)$, mostly women (70\%), who smoked 19.6 cigarettes per day $(S D=8.5)$, had a smoking history of 21.2 years $(S D=11.2)$, and had made 3.9 previous attempts to quit $(S D=5.3)$. Mean cigarette dependence was $4.9(S D=2.5)$. After one month, 197 participants (63\% of the complete cases) reported to be currently executing a quit attempt. After six months, 95 participants (51\% of the complete cases) reported to be executing a quit attempt. Complete case analysis showed that 118 participants had quit smoking (measured by 7-day point prevalence) after one month (38\%) and 85 participants after six months (45\%). When participants who were lost to follow-up are treated as smokers these percentages drop to $15 \%$ and $11 \%$, respectively.

\section{Attrition}

At follow-up after one month, 402 participants (40\%) filled out the online questionnaire. Logistic regression analysis revealed that participants who dropped out after one month were more likely to be less educated $(\mathrm{OR}=0.75, p<.01$, 95\% CI: 0.61-0.92). After six months, 232 participants (23\%) filled out the web questionnaire and the only factor that predicted dropout was having a smoking partner $(\mathrm{OR}=1.38, p=.05,95 \% \mathrm{CI}: 1.00-1.93)$.

Among smokers prepared to quit within a month, 313 participants (40\%) filled out the online questionnaire 
after one month. Participants who dropped out after one month were more likely to be less educated $(\mathrm{OR}=0.76$, $p<.05$, 95\% CI: 0.61-0.96), had a higher chance of having a partner that smokes $(\mathrm{OR}=1.44, p<.05$, 95\% CI: 1.04-2.00), and were younger $(\mathrm{OR}=0.97, p<.01$, 95\% CI: 0.95-0.98). After six months, 187 participants (23\%) filled out the web questionnaire and factors that predicted dropout were having a partner who smokes $(\mathrm{OR}=1.47, p<.05,95 \% \mathrm{CI}: 1.01-2.15)$ and age $(\mathrm{OR}=0.97$, $p<.01$, 95\% CI: 0.95-0.99)

\section{Plans and their enactment}

Our first goal pertains to the analysis of plans chosen and executed. As can be noted from Table 1, the most popular plans for the total population at baseline were to read information about how to quit successfully (89.4\%), to break the habit of smoking at specific times and places $(85.8 \%)$, and to choose a specific date to quit (82.2\%). At follow-up one month later (T2), we assessed which of the 12 plans participants had executed. Results reveal that reading information about how to quit successfully was the plan that was executed most $(68.4 \%$ of the complete cases). Informing people in the environment that you are about to quit smoking and choosing a specific date to quit were plans executed by roughly half of the participants (49.5\% and $50.7 \%$, respectively). At the second follow-up six months after baseline (T3), a similar pattern was observed, with reading information about how to quit successfully still being the most executed plan $(62.9 \%)$, followed by choosing a specific date to quit $(58.6 \%)$, and doing something different when you feel like smoking (53.4\%). Making non-smoking agreements and finding a buddy were the least popular plans and were carried out by only a fifth of the participants (T2 and T3). As can be noted, these figures were only marginally different for smokers who were prepared to quit within a month.

\section{Effects of specific preparatory plans and plan enactment}

The second goal of the study aims at assessing which plans were related to attempts to quit and smoking cessation. Table 2 shows the results of the univariate logistic regression analyses, in which attempts to quit and actual smoking cessation were regressed on each plan separately. The results reveal that associations of plan enactment with quit attempt at $\mathrm{T} 2$ and smoking cessation at $\mathrm{T} 2$ and T3 were stronger than the association of action planning, both for the total population and for smokers prepared to quit within one month.

Table 2, furthermore, reveals that enactment of the six following plans is associated with increased quit attempt rates at T2 and smoking cessation at T2 and T3 for both groups: removing all tobacco products from your house, choosing a specific quit date, informing people in your environment that you are going to quit, doing something different when you feel like smoking, thinking about preventing weight increase, removing all ash trays, and breaking your habit of smoking at specific times and places.

Table 3 shows the results of the multivariate logistic regression analyses (with age, gender, education, selfefficacy, cigarette dependence, and intention to quit as covariates), in which all plan enactments were included. VIF $($ all $<2)$ and tolerance values $($ all $>0.5)$ revealed no threats for multicollinearity between the items and power analysis indicated that, despite our relatively small sample size of 187 participants at the second follow-up (T3), there was sufficient power to conduct the analyses (Total sample: $N=232$, observed $R^{2}=0.36$, power $=0.99$; PR sample: $N=187$, observed $R^{2}=0.33$, power $=0.99 ;[52])$.

The results of Table 3 confirm the pattern identified in Table 2, that making plans is less predictive of smoking cessation behavior than plan enactment. Most Odds Ratios were considerably higher for plan enactment than for making plans. Many enacted plans that predicted quit attempt and smoking cessation had a comparable strength both for the total population and smokers prepared to quit within one month. As can be noted, the differences in the ORs between these two groups were mostly marginal.

Finally, two plan enactments predicted smoking cessation consistently at both follow-ups: removing all tobacco products from the house, and choosing a specific date to quit. Table 3 , furthermore, reveals that finding a buddy with whom to quit, making nonsmoking agreements, and thinking about how to cope with difficult situations before attempting to quit were relatively ineffective plans. They had no significant association with any of the three outcomes for the total population. Moreover, finding a buddy with whom to quit was found to be negatively associated with quit attempt rates (T2) for smokers prepared to quit within a month.

\section{Intention is related to action plan development}

Next, we assessed which factors were associated with making action plans. As suggested by Hypothesis 1, we found higher levels of action planning in smokers who intended to quit within the next month $(M=3.80$, $S D=0.54)$ than in those intending to quit within a year $(M=3.60, S D=0.55 ; t(1003)=4.77, p<.001)$. Similarly, participants who intended to quit smoking within the next month had executed significantly more plans at follow-up one month later $(M=5.04, S D=2.71)$ than those intending to quit within a year $(M=3.34$, $S D=2.56 ; t(400)=5.28, p<.001)$. Multivariate linear regression analysis was used to assess which other 
Table 2 Action plans and goal enactment predicting quit attempt and smoking cessation (Univariate analyses)

\begin{tabular}{|c|c|c|c|c|c|c|c|}
\hline & & \multicolumn{2}{|c|}{ Quit attempt (T2) } & \multicolumn{2}{|c|}{$\begin{array}{l}7 \text { day point } \\
\text { prevalence (T2) }\end{array}$} & \multicolumn{2}{|c|}{$\begin{array}{c}7 \text { day point } \\
\text { prevalence (T3) }\end{array}$} \\
\hline & & $\overline{\mathrm{OR}_{\mathrm{TOT}}}$ & $\mathrm{OR}_{\mathrm{PR}}$ & $\overline{\mathrm{OR}_{\mathrm{TOT}}}$ & $\mathrm{OR}_{\mathrm{PR}}$ & $\overline{\mathrm{OR}_{\mathrm{TOT}}}$ & $\mathrm{OR}_{\mathrm{PR}}$ \\
\hline \multirow[t]{2}{*}{ To remove all tobacco products from your house } & $A P$ & 1.09 & 1.12 & $1.34^{* *}$ & $1.37^{* *}$ & 1.07 & 1.09 \\
\hline & PE & $3.59^{* * *}$ & $2.59^{* * *}$ & $4.50^{* * *}$ & $2.94^{* * *}$ & $3.99^{* * *}$ & $3.44^{* * *}$ \\
\hline \multirow[t]{2}{*}{ To choose a specific quit date } & $\mathrm{AP}$ & $1.59^{* * *}$ & $1.29^{*}$ & $1.77^{* * *}$ & $1.38^{*}$ & $1.33^{*}$ & 1.13 \\
\hline & PE & $3.02^{* * *}$ & $2.26^{* *}$ & $3.07^{* * *}$ & $2.55^{* * *}$ & $3.79^{* * *}$ & $3.96^{* * *}$ \\
\hline \multirow{2}{*}{$\begin{array}{l}\text { To inform people in your environment that you are about to } \\
\text { quit smoking }\end{array}$} & AP & $1.27^{* *}$ & $1.23^{*}$ & $1.45^{* * *}$ & $1.34^{* *}$ & $1.18^{\dagger}$ & 1.18 \\
\hline & PE & $2.63^{* * *}$ & $2.72^{* * *}$ & $2.31^{* * *}$ & $1.95^{* *}$ & $2.35^{* *}$ & $2.46^{* *}$ \\
\hline \multirow[t]{2}{*}{ To do something different when you feel like smoking } & $\mathrm{AP}$ & 1.17 & 1.08 & 1.14 & 1.17 & 1.02 & 0.96 \\
\hline & PE & $3.12^{* * *}$ & $2.82^{* * *}$ & $2.52^{* * *}$ & $2.01^{* *}$ & $2.42^{* *}$ & $1.96^{*}$ \\
\hline \multirow{2}{*}{$\begin{array}{l}\text { To think about how you can prevent weight increase after } \\
\text { you have quit smoking }\end{array}$} & $A P$ & 0.97 & 0.94 & 1.13 & 1.17 & 1.12 & 1.13 \\
\hline & PE & $1.77^{* *}$ & 1.45 & $1.70^{*}$ & $1.51^{\dagger}$ & $2.03^{* *}$ & $1.79^{*}$ \\
\hline \multirow[t]{2}{*}{ To remove all ashtrays from the house } & $\mathrm{AP}$ & 1.06 & 1.05 & $1.13^{\dagger}$ & 1.10 & 1.08 & 1.06 \\
\hline & PE & $2.08^{* *}$ & 1.48 & $1.54^{\dagger}$ & 1.17 & $2.50^{* *}$ & $2.08^{*}$ \\
\hline \multirow[t]{2}{*}{ To search for certain aids to help you quit smoking } & AP & 1.06 & 1.10 & 1.02 & 1.08 & 0.89 & 0.95 \\
\hline & PE & $2.27^{* * *}$ & $2.09^{* *}$ & $1.98^{* *}$ & $1.86^{*}$ & 1.33 & 1.09 \\
\hline \multirow[t]{2}{*}{ To break your habit of smoking at specific times and places } & $A P$ & $1.40^{* *}$ & 1.22 & 1.16 & 1.06 & 1.25 & $1.45^{\dagger}$ \\
\hline & $\mathrm{PE}$ & $1.58^{*}$ & 1.25 & 1.21 & 1.05 & $2.74^{* * *}$ & $2.73^{* *}$ \\
\hline \multirow[t]{2}{*}{ To read information about how to quit successfully } & AP & $1.47^{* *}$ & $1.40^{*}$ & $1.37^{*}$ & 1.29 & 0.94 & 0.78 \\
\hline & PE & $1.58^{*}$ & 1.21 & 1.26 & 1.19 & 1.58 & $1.75^{\dagger}$ \\
\hline \multirow{2}{*}{$\begin{array}{l}\text { To think about how to cope with difficult situations before } \\
\text { your quit attempt }\end{array}$} & AP & 1.17 & 1.01 & 1.07 & 0.91 & 0.97 & 0.85 \\
\hline & PE & 1.36 & 1.36 & $1.46^{\dagger}$ & 1.45 & 1.55 & 1.48 \\
\hline \multirow{2}{*}{$\begin{array}{l}\text { To make non-smoking agreements with the individuals } \\
\text { living with you }\end{array}$} & AP & 0.96 & 0.99 & 1.05 & 1.13 & 0.98 & 1.08 \\
\hline & PE & 1.29 & 1.26 & 1.15 & 1.09 & 1.62 & 1.61 \\
\hline \multirow[t]{2}{*}{ To find a buddy so you can quit together } & AP & 0.95 & 0.89 & 0.98 & 1.03 & 0.97 & 1.04 \\
\hline & PE & 0.88 & $0.59^{\dagger}$ & 1.01 & 0.87 & 1.14 & 1.04 \\
\hline
\end{tabular}

$A P=$ Action Plans; $P E=$ Plan Enactment; $\dagger p<.10,{ }^{*} p<.05,{ }^{* *} p<.01,{ }^{* * *} p<.001$.

Total sample: $N(\mathrm{~T} 2)=402 ; N(\mathrm{~T} 3)=232 ;$ PR sample: $N(\mathrm{~T} 2)=313 ; N(\mathrm{~T} 3)=187$.

factors were related to action planning. Besides the effect of intention, the results revealed that being older, being female, having relatively high levels of cigarette dependence, perceiving more positive and negative consequences (pros and cons) of quitting, and high self-efficacy toward quitting were all associated with higher levels of action planning at baseline (Table 4).

\section{Intention is related to plan enactment}

As suggested by Hypothesis 2a, the multivariate linear regression analyses depicted in Table 4 also reveal that intention was positively related to the number of plans executed at T2. In addition, younger participants and participants who reported higher levels of action planning at baseline (as suggested by Hypothesis $2 \mathrm{~b}$ ) executed more plans. After six months (T3), the effects of intention and age dissipated; action planning at baseline was the only predictor of plan execution.

\section{Action planning and plan enactment are related to smoking cessation}

Hypotheses 3 and 4 postulate that action planning and plan enactment are related to smoking cessation. The multivariate logistic regression analyses in Table 5 reveal that the level of action planning at baseline only predicted smoking cessation for smokers motivated to quit within a month at the first follow-up, and had only a borderline significant effect on smoking cessation for the total population at the first follow-up. Plan enactment, however, consistently predicted smoking cessation for both groups, as suggested by Hypothesis 4. Other predictors of non-smoking after six months for the total sample were low levels of depression, having a nonsmoking partner, and intending to quit within the next month. Low levels of cigarette dependence and high self-efficacy to quit were borderline significant predictors. Other factors predicting nonsmoking after six 
Table 3 Action plans and goal enactment predicting quit attempt and smoking cessation (Multivariate analyses)

\begin{tabular}{|c|c|c|c|c|c|c|c|}
\hline & & \multicolumn{2}{|c|}{ Quit attempt (T2) } & \multicolumn{2}{|c|}{$\begin{array}{c}7 \text { day point } \\
\text { prevalence (T2) }\end{array}$} & \multicolumn{2}{|c|}{$\begin{array}{c}7 \text { day point } \\
\text { prevalence (T3) }\end{array}$} \\
\hline & & $\overline{\mathrm{OR}_{\mathrm{TOT}}}$ & $\mathrm{OR}_{\mathrm{PR}}$ & $\overline{\mathrm{OR}_{\mathrm{TOT}}}$ & $\mathrm{OR}_{\mathrm{PR}}$ & $\overline{\mathrm{OR}_{\mathrm{TOT}}}$ & $\mathrm{OR}_{\mathrm{PR}}$ \\
\hline \multirow[t]{2}{*}{ To remove all tobacco products from your house } & $A P$ & 0.93 & 1.00 & $1.25^{\dagger}$ & $1.24^{*}$ & 1.08 & 0.92 \\
\hline & PE & $1.70^{+}$ & $1.80^{+}$ & $3.55^{* * *}$ & $2.96^{* *}$ & $3.40^{* *}$ & $3.56^{* *}$ \\
\hline \multirow[t]{2}{*}{ To choose a specific quit date } & $\mathrm{AP}$ & $1.25^{\dagger}$ & 1.22 & 1.24 & 1.22 & 1.03 & 1.09 \\
\hline & $P E$ & $1.88^{*}$ & $1.62^{\dagger}$ & $1.95^{*}$ & $2.06^{*}$ & $3.34^{* * *}$ & $3.65^{* *}$ \\
\hline \multirow[t]{2}{*}{ To inform people in your environment that you are about to quit smoking } & $A P$ & $1.19^{\dagger}$ & $1.23^{+}$ & $1.30^{*}$ & $1.26^{*}$ & 1.16 & 1.14 \\
\hline & PE & $1.75^{*}$ & $2.48^{* *}$ & 1.24 & 1.21 & 1.47 & 1.59 \\
\hline \multirow[t]{2}{*}{ To do something different when you feel like smoking } & AP & 1.02 & 0.98 & 1.14 & 1.02 & 0.89 & 0.98 \\
\hline & PE & $2.44^{* *}$ & $2.74^{* *}$ & $1.94^{*}$ & $1.75^{*}$ & 1.31 & 0.89 \\
\hline \multirow{2}{*}{$\begin{array}{l}\text { To think about how you can prevent weight increase after you have quit } \\
\text { smoking }\end{array}$} & AP & 0.91 & 0.94 & 1.10 & $1.20^{\dagger}$ & 1.20 & 1.18 \\
\hline & PE & $1.58^{+}$ & 1.40 & 1.40 & 1.36 & $1.86^{\dagger}$ & 1.53 \\
\hline \multirow[t]{2}{*}{ To remove all ashtrays from the house } & $\mathrm{AP}$ & 1.01 & 1.07 & 0.98 & 1.04 & 1.06 & 1.11 \\
\hline & PE & 0.95 & 0.89 & $0.54^{+}$ & $0.57^{\dagger}$ & 0.94 & 0.71 \\
\hline \multirow[t]{2}{*}{ To search for certain aids to help you quit smoking } & AP & 1.10 & 1.08 & 1.08 & 1.02 & 0.99 & 0.93 \\
\hline & PE & $1.63^{+}$ & $1.80^{\dagger}$ & 1.37 & 1.45 & 0.94 & 0.82 \\
\hline \multirow[t]{2}{*}{ To break your habit of smoking at specific times and places } & $A P$ & 1.18 & 1.09 & 0.86 & 0.84 & $1.45^{\dagger}$ & 1.09 \\
\hline & PE & 0.87 & 0.68 & 0.63 & 0.63 & 1.71 & $2.30^{+}$ \\
\hline \multirow[t]{2}{*}{ To read information about how to quit successfully } & AP & $1.43^{*}$ & $1.50^{*}$ & $1.48^{*}$ & 1.17 & 0.80 & 0.91 \\
\hline & PE & 0.94 & 0.69 & 0.79 & 0.85 & 0.96 & 1.18 \\
\hline \multirow[t]{2}{*}{ To think about how to cope with difficult situations before your quit attempt } & $A P$ & 1.01 & 0.87 & $0.79^{+}$ & 0.85 & 0.88 & $0.81^{\dagger}$ \\
\hline & PE & 0.76 & 0.76 & 1.07 & 1.07 & 0.77 & 0.70 \\
\hline \multirow[t]{2}{*}{ To make non-smoking agreements with the individuals living with you } & AP & 0.88 & 0.91 & 0.98 & 0.94 & 0.91 & 0.95 \\
\hline & PE & 0.94 & 1.32 & 0.81 & 0.86 & 0.72 & 0.89 \\
\hline \multirow[t]{2}{*}{ To find a buddy so you can quit together } & AP & 0.96 & 0.88 & 0.97 & 0.94 & 0.96 & 0.98 \\
\hline & PE & $0.55^{+}$ & $0.29^{* *}$ & 0.66 & 0.59 & 0.73 & 0.66 \\
\hline
\end{tabular}

$A P$ action plans; $P E$ plan enactment; $\dagger p<.10,{ }^{*} p<.05,{ }^{* *} p<.01,{ }^{* * *} p<.001$. Total sample: $N(\mathrm{~T} 2)=402 ; N(\mathrm{~T} 3)=232 ;$ PR sample: $N(\mathrm{~T} 2)=313 ; N(\mathrm{~T} 3)=187$.

months for smokers motivated to quit were depression and self-efficacy.

Furthermore, we tested potential mediation effects in order to explore how much of the predictive value of action planning could be attributed to the actual execution of such a plan [53]. Results reveal that $81 \%$ of the direct effect of action planning was mediated by plan enactment. Using the Sobel test, this mediation was found to be significant $(t=1.95, p<.05$; [54]).

Finally, we translated the effects of plan enactment into actual quitting percentages by creating two groups: participants low in plan enactment (less than the median of five after six months) and participants high in plan enactment (more than the median of five after six months). This revealed that $29 \%$ of the smokers who completed less plans than the median had quit successfully after six months versus $59 \%$ of the smokers who completed more than the median (complete case analysis; $N=232 ; \chi^{2}=21.05$, $p<.001)$.
Similarly, participants who intended to quit smoking within the next month had executed significantly more plans at follow-up one month later $(M=5.04, S D=2.71)$ than those intending to quit within a year $(M=3.34$, $S D=2.56 ; t(400)=5.28, p<.001)$.

\section{Discussion}

Planning can have a significant positive impact on changing health behavior [55-59]. However, relatively little is known about which factors are related to action planning and plan enactment, and how they are related to smoking cessation. Our results suggest seven plans that were related to smoking cessation at follow-up after six months. The multivariate analysis identified that the execution of two specific plans was most significantly related to abstinence at follow-up, namely removing all tobacco products from the house and choosing a specific date to quit. The latter finding confirms the previous work of Balmford and colleagues [60]. Yet, it is conceivable that 
Table 4 Baseline variables associated with action planning and plan enactment

\begin{tabular}{|c|c|c|c|}
\hline & $\begin{array}{c}\text { Action } \\
\text { planning (T1) } \\
\beta\end{array}$ & $\begin{array}{c}\text { Executed } \\
\text { plans (T2) } \\
\beta\end{array}$ & $\begin{array}{c}\text { Executed } \\
\text { plans (T3) } \\
\beta\end{array}$ \\
\hline \multicolumn{4}{|l|}{ Total Sample } \\
\hline Age & $.10^{* * *}$ & $-.12^{*}$ & -.07 \\
\hline $\begin{array}{l}\text { Gender } \\
(0=\text { male })\end{array}$ & $.07^{* *}$ & .04 & .09 \\
\hline Education & $.04^{+}$ & .01 & .11 \\
\hline Depression & .01 & .07 & .05 \\
\hline Quit attempts & -.01 & .05 & .10 \\
\hline Nicotine dep. & $.11^{* * *}$ & $.07^{\dagger}$ & .05 \\
\hline Pros of quitting & $.29^{* * *}$ & .03 & .06 \\
\hline Cons of quitting & $.08^{* *}$ & .05 & .10 \\
\hline SI - children & -.02 & .02 & .01 \\
\hline SI - partner & .01 & .01 & -.03 \\
\hline Self-efficacy & $.18^{* * *}$ & .01 & .05 \\
\hline Intention to quit & $.07^{* *}$ & $.15^{* *}$ & -.01 \\
\hline Action planning & - & $.37^{* * *}$ & $.32^{* * *}$ \\
\hline \multicolumn{4}{|c|}{ Smokers In Preparation } \\
\hline Age & $.10^{* *}$ & $-.13^{*}$ & -.01 \\
\hline $\begin{array}{l}\text { Gender } \\
(0=\text { male })\end{array}$ & $.10^{*}$ & .08 & .12 \\
\hline Education & $.06^{\dagger}$ & .03 & $.18^{*}$ \\
\hline Depression & .02 & .06 & .06 \\
\hline Quit attempts & -.03 & .07 & .07 \\
\hline Nicotine dep. & $.10^{* *}$ & .06 & .03 \\
\hline Pros of quitting & $.29^{* * *}$ & .03 & .09 \\
\hline Cons of quitting & .06 & .07 & .13 \\
\hline SI - children & -.01 & -.01 & -.01 \\
\hline SI - partner & .01 & -.05 & -.05 \\
\hline Self-efficacy & $.22^{* * *}$ & -.01 & .05 \\
\hline Action planning & - & $.37^{* * *}$ & $.27^{* *}$ \\
\hline
\end{tabular}

$S I=$ Social influence $\dagger p<.10,{ }^{*} p<.05,{ }^{* *} p<.01,{ }^{* * *} p<.001$.

the five plans that were not significant anymore in the multivariate analysis are related to these two plans and that for selection of effective plans to quit smoking, a practitioner might want to choose to recommend these seven plans. In addition, we identified plans that were not related to smoking cessation after one and six months. They included finding a buddy with whom to quit, making non-smoking agreements, and thinking about how to cope with difficult situations before attempting to quit. The latter finding is in contrast to other notions of the importance of coping plans. One explanation is that this type of formulation may have been too broad and may need to be replaced by specific implementation intentions for specific difficult situations.
Table 5 Factors associated with quit attempt and smoking cessation

\begin{tabular}{|c|c|c|c|c|c|c|}
\hline & \multicolumn{2}{|c|}{$\begin{array}{c}\text { Quit } \\
\text { attempt (T2) } \\
\end{array}$} & \multicolumn{2}{|c|}{$\begin{array}{c}7 \text { day point } \\
\text { prevalence (T2) } \\
\end{array}$} & \multicolumn{2}{|c|}{$\begin{array}{c}7 \text { day point } \\
\text { prevalence (T3) }\end{array}$} \\
\hline & $\mathrm{OR}_{\mathrm{TOT}}$ & $\mathrm{OR}_{\mathrm{PR}}$ & $\mathrm{OR}_{\text {TOT }}$ & $\mathrm{OR}_{\mathrm{PR}}$ & $\mathrm{OR}_{\mathrm{TOT}}$ & $\mathrm{OR}_{\mathrm{PR}}$ \\
\hline Age & 1.02 & 1.02 & 1.01 & 1.01 & 1.01 & 1.01 \\
\hline Gender $(0=$ male $)$ & $0.41^{*}$ & $0.42^{*}$ & 0.65 & 0.69 & 0.76 & 0.54 \\
\hline Education & 0.99 & 1.05 & 0.99 & 1.01 & 0.82 & 0.86 \\
\hline Depression & 0.97 & 0.97 & 0.95 & $0.94^{\dagger}$ & $0.92^{*}$ & $0.89^{*}$ \\
\hline Quit attempts & 0.98 & 0.97 & 0.99 & 0.99 & 0.95 & 0.95 \\
\hline Nicotine dep. & 0.94 & 0.91 & 0.92 & 0.93 & $0.87^{\dagger}$ & 0.90 \\
\hline Pros of quitting & 1.12 & 1.32 & 0.73 & 0.73 & 0.74 & 0.77 \\
\hline Cons of quitting & 1.02 & 0.93 & 0.76 & 0.78 & 0.86 & 0.84 \\
\hline Smoking children & 1.20 & 1.49 & 1.05 & 1.09 & 0.65 & 0.81 \\
\hline Smoking partner & 0.83 & 0.67 & 0.67 & $0.63^{\dagger}$ & $0.45^{*}$ & 0.56 \\
\hline Self-efficacy & 1.39 & 1.49 & 1.49 & 1.52 & $1.89^{\dagger}$ & $2.36^{*}$ \\
\hline Intention to quit & $3.86^{* * *}$ & - & $6.83^{* * *}$ & - & $2.60^{*}$ & - \\
\hline AP at baseline & 0.88 & 0.87 & $1.76^{\dagger}$ & $1.90^{*}$ & 0.72 & 0.71 \\
\hline PE after 1 month & $1.30^{* * *}$ & $1.27^{* * *}$ & $1.22^{* * *}$ & $1.20^{* *}$ & - & - \\
\hline PE after 6 months & - & - & - & - & $1.50^{*}$ & $1.48^{* * *}$ \\
\hline
\end{tabular}

As suggested by Hypothesis 1, higher levels of action planning were observed in smokers who intended to quit within the next month. Additional factors that correlated with baseline action planning were being older, being female, high levels of cigarette dependence, perceiving more positive consequences (pros) of quitting, perceiving more negative consequences (cons) of quitting, and having high self-efficacy toward quitting. Although the importance of these factors for predicting successful quitting in (subgroups of) smokers has been documented by several other studies (see e.g., [30,61-64]), their relation to the process of action planning was not assessed.

In line with Hypothesis 2, our results reveal that the intention to quit and action planning at baseline had a significant and positive influence on the number of plans executed. Other studies have already noted that action planning will be more likely to occur under high levels of motivation $[5,17,58]$, but not that these factors are also related to plan enactment. Participants who intended to quit smoking within the next month had executed, on average, two and a half more action plans at follow-up one month later than their peers who intended to quit within a year. These findings are confirmed by a recent study that found the greatest effect of preparatory planning among smokers who tried to quit by following a group course [65]. At the six-month follow-up, the effect of intention was no longer significant, and action planning at baseline was the only significant predictor of plan enactment. 
We found support for Hypothesis 3 stating that planning is associated with quit attempts and smoking cessation. Several plans have been found to be associated with quit attempts and smoking cessation. Yet, when controlling for other factors we noted that the general factor of planning was only a significant predictor of smoking cessation at first follow-up and only for smokers in preparation. We also found support for Hypothesis 4, postulating that plan enactment would significantly predict non-smoking status at follow-up. Other significant predictors of smoking cessation were depression, and self-efficacy. Of interest is the fact that our findings do not strongly support studies that suggest an important role for cigarette addiction in understanding cessation maintenance $[66,67]$. We only found a borderline significant effect of cigarette dependence in predicting smoking cessation in the total population at the last-follow up.

Another finding was that baseline action planning was not a significant independent predictor of cessation outcome after controlling for other factors, including plan enactment. These results suggest that the effects of action planning may be mediated by plan enactment. We indeed found support for this mediation effect, since our results estimated that $81 \%$ of the direct effect of action planning was mediated by plan enactment. Furthermore, our results revealed that $29 \%$ of the smokers who completed fewer plans than the median had quit successfully after six months versus $59 \%$ of the smokers who completed more than the median. Action planning is an important precondition for plan enactment, because planning is obviously more likely to lead to enactment of certain goals. Plan enactment after one month was predicted by baseline intentions and baseline action planning and, after six months, only by action planning. This last finding illustrates the importance of translating global baseline intentions into specific plans.

Comparing the findings concerning the plans made and executed between our total population with those prepared to quit within one month showed similarity in the plans made and executed. A notable difference was the significance of breaking habits at the last follow-up, which appeared to be a significant predictor of smoking cessation among those prepared to quit. This finding supports other research that outlines the impact of habits on behavior [68], but even the importance of planning to break habits. We also found that smokers motivated to quit within one month had executed more plans. This suggests that adopting and executing effective plans can be productive to aid smoking cessation. This is supported by our finding showing that those who completed more plans than the medium were also more effective in remaining non-smokers after six months.

Our study is subject to some limitations. First, we did not assess differences in levels of specificity of the action plans. Van Osch and colleagues [16] found that plan specificity positively predicts point prevalence abstinence; medium to highly specific planning resulted in higher abstinence rates than less specific planning. Hence, assessing levels of specificity in future studies is recommended. Second, we did not make two separate scales of preparatory plans and coping plans in order to assess a potential different impact of both types of plans. Sniehotta, 2005 [13]; Sniehotta, 2009 [14]; de Vet, 2011 [34], nor did we assess the exact timing of plan enactment (e.g. before or after the quit attempt). Future studies should also assess the role of both types of planning [69] and assess the potential differential impact of preparatory and coping plan enactment. Third, our study had low retention rates at follow-up. However, because only low educational level and having a partner that smokes were related to dropout, the likelihood of a bias that those who quit smoking were more likely to provide follow-up data is small.

\section{Conclusion}

Our results reveal clearly the importance of the assessment of both action planning and plan enactment, factors that were also identified in a recent review of behavior-change strategies for smoking cessation [70]. Application of these behavior change strategies can be used by various methods such as mass-media campaigns, health counseling, and computer tailoring [16,62,71-73]. Our results support notions identified by others, such as Zhou and colleagues [74] indicating that motivational factors may be relevant for predicting smoking cessation attempts, but that other factors are also involved when predicting smoking cessation maintenance. Future studies about action planning should not only assess which plans are made but also which plans are enacted. Our study reveals that smoking cessation is more likely to be successful when effective action plans are both formulated and executed. Our study also suggests that not all action plans are necessarily predictive of effective smoking cessation. Haug and colleagues [64], for instance, found that some constructs of the Transtheoretical model (i.e., helping relationships, commitment to change, coping with temptations) were univariately related to smoking cessation, but did not have a unique prediction in a more comprehensive model. This illustrates the importance of longitudinal and experimental research as well as the use of a comprehensive model to identify which factors predict smoking cessation. Furthermore, it is relevant to study differences in decision-making for volitionally chosen and assigned action plans [45]. Although participation in goal setting may increase goal commitment [75], it is also conceivable that participants may choose ineffective action plans, as can be seen from the results in our study. Yet, it may be likely that a goal chosen with a high degree of confidence in the decision-making procedure used is more likely to be enacted than one fraught with uncertainty [76]. This 
suggests that action planning and levels of self-efficacy toward planning enactment may have interactive effects. Finally, some studies suggest the importance of unplanned attempts to quit, but cannot really exclude whether or not action plans were not made, and used retrospective designs (see e.g., [77-79]). Other studies do not support these claims (see e.g., [80,81]). Our study clearly demonstrates that discussions about whether or not to use planning need better documentation than has been made in the past, namely by a clear assessment of plans made and enacted.

\section{Competing interests}

$\mathrm{HdV}$ is also scientific director of Vision2Health, a company implementing evidence based eHealth programs.

\section{Authors' contribution}

HdV conceived the study, supervised the development and implementation of the study, and drafted the manuscript. ME performed the statistical analyses and participated in the drafting of the manuscript. CB was participated in the development and implementation of the study and the drafting of the manuscript. All authors read and approved the final manuscript.

\section{Authors' information}

$\mathrm{HdV}$ is professor in health communication at Maastricht University with a special interest in testing social cognitive models, designing computer tailored eHealth interventions, and various other types of health communications for various topics. ME is researcher in health communication at Maastricht University with special interests in theory building and testing and HIV prevention. CB is assistant professor in health psychology with special interests in smoking cessation.

\section{Acknowledgements}

We thank: Fam te Poel for her contributions concerning questionnaire development and data gathering; Iman Elfeddali for her comments on an earlier version; and Jennifer Roche for checking our Euro-English.

\section{Funding}

The Netherlands Organization for Health Research and Development (62000002).

\section{Author details}

${ }^{1}$ Care and Public Health Research Institute, Department of Health Promotion, Maastricht University, Maastricht, The Netherlands. 'Faculty of Psychology, Open University of the Netherlands, PO Box 2960, Heerlen 6401 DL, The Netherlands.

Received: 19 March 2012 Accepted: 12 April 2013

Published: 26 April 2013

\section{References}

1. West R, McNeill A, Raw M: Smoking cessation guidelines for health professionals: an update. Health Education Authority. Thorax 2000 55(12):987-999.

2. Godin G, Conner M: Intention-behavior relationship based on epidemiologic indices: an application to physical activity. Am J Heal Promot 2008, 22(3):180-182.

3. Orbell S, Sheeran P: 'Inclined abstainers': a problem for predicting healthrelated behaviour. Br J Soc Psychol 1998, 37(Pt 2):151-165.

4. Bagozzi RP, Baumgartner $H$, Yi Y: State versus action orientation and the theory of reasoned action: an application to coupon usage. J Consum Res 1992, 18:505-518. march 1992.

5. Gollwitzer PM: Implementation intentions. Strong effects of simple plans. Am Psychol 1999, 54(7):493-503.

6. Heckhausen J, Baltes PB: Perceived controllability of expected psychological change across adulthood and Old Age. J Gerontol 1991, 46(4):P165-P173. July 1, 1991.
7. Schwarzer R (Ed): Self-efficacy: Thought control of action. Washington, DC: Hemisphere; 1992.

8. de Vries H, Mudde A, Leijs I, Charlton A, Vartiainen E, Buijs G, Clemente MP, Storm H, Gonzalez Navarro A, Nebot M, Prins T, Kremers S: The European smoking prevention framework approach (EFSA): an example of integral prevention. Health Education Research; Theory and Practice 2003, 18(5):611-626

9. Leventhal $H$, Nerenz DR, Steele DJ: Illness representations and coping with health threats. In Handbook of Psychology and Health. Edited by Baum A, Taylor SE, Singer JE. Hillsdale: Erlbaum; 1984:219-252.

10. Leventhal $H$, Singer $R$, Jones $S$ : Effects of fear and specificity of recommendation upon attitudes and behavior. J Personal Soc Psychol 1965, 2(1):20-29.

11. Leventhal H, Watts JC, Pagano F: Effects of fear and instructions on how to cope with danger. J Personal Soc Psychol 1967, 6(3):313-321.

12. Abraham C, Sheeran P: Implications of goal theories for the theoies of reasoned action and planned behavior. Current Psychology: developmental, learning, personality, social 2003, 22(3):264-280

13. Sniehotta FF, Scholz U, Schwarzer R: Bridging the intention-behaviour gap: Planning, self-efficacy, and action control in the adoption and maintenance of physical exercise. Psychol Heal 2005, 20(2):143-160.

14. Sniehotta FF: Towards a theory of intentional behaviour change: Plans, planning, and self-regulation. Br J Heal Psychol 2009, 14(2):261-273.

15. Bergeson SC, Dean JD: A systems approach to patient-centered care. JAMA 2006, 296(23):2848-2851. December 20, 2006.

16. van Osch $L$, Lechner $L$, Reubsaet $A$, Wigger $S$, De Vries H: Relapse prevention in a national smoking cessation contest: Effects of coping planning. Br J Heal Psychol 2008, 13(3):525-535.

17. Van Osch L, Lechner L, Reubsaet A, De Vries H: From theory to practice: An explorative study into the instrumentality and specificity of implementation intentions. Psychol Heal 2010, 25(3):351-364

18. Handley M, MacGregor K, Schillinger D, Sharifi C, Wong S, Bodenheimer T: Using action plans to help primary care patients adopt healthy behaviors: a descriptive study. J Am Board Fam Med 2006, 19(3):224-231. May 1, 2006.

19. MacGregor K, Handley M, Wong S, Sharifi C, Gjeltema K, Schillinger D, et al: Behavior-change action plans in primary care: a feasibility study of clinicians. J Am Board Fam Med 2006, 19(3):215-223. May 1, 2006.

20. Austin JT, Vancouver JB: Goal constructs in psychology: structure, process and content. Psychol Bull 1996, 120(3):338-375.

21. De Vries H, Dijk F, Wetzels J, Mudde A, Kremers S, Ariza C, et al: The European Smoking prevention Framework Approach (ESFA): effects after 24 and 30 months. Heal Educ Res 2006, 21(1):116-132.

22. De Vries H, Kremers S, Smeets T, Eijmael K: The effectiveness of tailored feedback and action plans in an intervention addressing multiple health behaviors. Am J Heal Promot 2008, 22(6):417-425.

23. Abraham $C$, Sheeran $P$, Orbell $S$ : Can social cognitive models contribute to the effectiveness of HIV-preventive behavioural interventions? A brief review of the literature and a reply to Joffe $(1996 ; 1997)$ and Fife-Schaw (1997). Br J Med Psychol 1998, 71(Pt 3):297-310.

24. Sheeran P, Webb TL, Gollwitzer PM: The interplay between goal intentions and implementation intentions. Personality and Social Psychology Bulletin 2005, 31(1):87-98.

25. Bandura A: Human agency in social cognitive theory. Am Psychol 1989, 44(9):1175-1184

26. Latham GP, Locke EA: Enhancing the benefits and overcoming the pitfalls of goal setting. Organ Dyn 2006, 35(4):332-340.

27. Stock J, Cervone D: Proximal goal-setting and self-regulatory processes. Cogn Ther Res 1990, 14(5):483-498.

28. Locke EA, Latham GP: Building a practically useful theory of goal setting and task motivation. Am Psychol 2002, 57(9):705-717.

29. Bagozzi RP, Edwards EA: Goal setting and goal pursuit in the regulation of body weight. Psychol Heal 1998, 13(4):593-621.

30. Prochaska JO, DiClemente CC: Stages and processes of self-change of smoking: toward an integrative model of change. J Consult Clin Psychol 1983, 51(3):390-395.

31. Bartholomew LK, Mullen PD: Five roles for using theory and evidence in the design and testing of behavior change interventions. J Public Health Dent 2011, 71:S20-S33.

32. Bryan A, Fisher J, Fisher W: Tests of the mediational role of preparatory safer sexual behavior in the context of the theory of planned behavior. Heal Psychol 2002, 21(1):71-80. 
33. Goebbels AF, Nicholson JM, Walsch K, de Vries H: Teachers' reporting of suspected child abuse and neglect: behaviour and determinants. Heal Educ Res 2008, 23(6):941-951.

34. de Vet E, Gebhardt WA, Sinnige J, Van Puffelen A, Van Lettow B, de Wit JBF Implementation intentions for buying, carrying, discussing and using condoms: the role of the quality of plans. Heal Educ Res 2011, 26(3):443-455.

35. Lippke S, Ziegelmann JP, Schwarzer R: Stage-specific adoption and maintenance of physical activity: testing a three-stage model. Psychology of Sport and Exercise 2005, 6(5):585-603.

36. Gollwitzer PM, Sheeran P: Implementation Intentions and Goal Achievement: A Meta-Analysis of Effects and Processes. In Advances in Experimental Social Psychology. Edited by Zanna MP. San Diego: Academic Press; 2006:69-119.

37. Jackson C, Lawton R, Knapp P, Raynor DK, Conner M, Lowe C, et al: Beyond intention: do specific plans increase health behaviours in patients in primary care? A study of fruit and vegetable consumption. Soc Sci Med 2005, 60(10):2383-2391.

38. Rutter D, Steadman $L$, Quine L: An implementation intentions intervention to increase uptake of mammography. Ann Behav Med 2006, 32(2):127-134

39. Skår S, Sniehotta FF, Molloy GJ, Prestwich A, Araújo-Soares V: Do brief online planning interventions increase physical activity amongst university students? A randomised controlled trial. Psychol Heal 2008, 26(4):399-417.

40. Webb TL, Sheeran P: Mechanisms of implementation intention effects: the role of goal intentions, self-efficacy, and accessibility of plan components. Br J Soc Psychol 2008, 47(3):373.

41. Hoving C, Mudde AN, de Vries $\mathrm{H}$ : Intention to adopt a smoking cessation expert system within a self-selected sample of Dutch general practitioners. Eur J Cancer Prev 2006, 15(1):82-86.

42. Hilberink S, Jacobs J, Schlosser M, Grol R, De Vries H: Characteristics of patients with COPD in three motivational stages related to smoking cessation. Patient Educ Couns 2006, 61:449-457.

43. Tindle HA, Shiffman S, Hartman AM, Bost JE: Switching to "lighter" cigarettes and quitting smoking. Tob Control 2009, 18(6):485-490.

44. Scholz U, Nagy G, Göhner W, Luszczynska A, Kliegel M: Changes in selfregulatory cognitions as predictors of changes in smoking and nutrition behaviour. Psychol Heal 2009, 24:545-561.

45. Dholakia U, Bagozzi R, Gopinath M: How formulating implementation plans and remembering past actions facilitate the enactment of effortful decisions. J Behav Decis Mak 2007, 20(4):343-364.

46. Te Poel F, Bolman C, Reubsaet A, de Vries H: Efficacy of a single computertailored e-mail for smoking cessation: results after 6 months. Heal Educ Res 2009, 24(6):930-940. December 1, 2009.

47. Dijkstra A, Bakker M, de Vries H: Subtypes within a sample of precontemplating smokers: a preliminary extension of the stages of change. Addict Behav 1997, 22(3):327-337.

48. Heatherton TF, Kozlowski LT, Frecker RC, Fagerstrom K-O: The fagerstrom test for nicotine dependence: a revision of the fagerstrom tolerance questionnaire. Br J Addict 1991, 86(9):1119-1127.

49. Comstock GW, Helsing KJ: Symptoms of depression in two communities. Psychol Med 1977, 6(04):551-563.

50. Dijkstra A, De Vries H, Roijackers J: Targeting smokers with Low readiness to change with tailored and nontailored self-help materials. Prev Med 1999, 28(2):203-211.

51. MacKinnon DP, Lockwood CM, Hoffman JM, West SG, Sheets V: A comparison of methods to test mediation and other intervening variable effects. Psycho Methods 2002, 7(1):83-104.

52. Cohen J, Cohen P, West SG, Aiken LS: Applied Multiple Regression/Correlation Analysis for the Behavioral Sciences. 3rd edition. Mahwah: Lawrence Erlbaum Associates; 2003

53. Mackinnon DP, Luecken $\sqcup:$ How and for whom? Mediation and moderation in health psychology. Heal Psychol 2008, 27(2 Suppl):S99-S100.

54. Mackinnon DP, Warsi G, Dwyer JH: A simulation study of mediated effect measures. Multivar Behav Res 1995, 30(1):41.

55. De Vries H, Mesters I, Riet J, Willems K, Reubsaet A: Motives of belgian adolescents for using sunscreen: the role of action plans. Cancer Epidemiol Biomarkers Prev 2006, 15(7):1360-1366. July 1, 2006.

56. Luszczynska A, Schwarzer R: Planning and self-efficacy in the adoption and maintenance of breast self-examination: a longitudinal study on self-regulatory cognitions. Psychol Heal 2003, 18(1):93-108.
57. Orbell S, Sheeran P: Motivational and volitional processes in action initiation: a field study of the role of implementation intentions. J App/ Soc Psychol 2000, 30(4):780-797

58. Sheeran P, Milne S, Webb TL, Gollwitzer PM: Implementation intentions and health behaviour. In Predicting health behaviour. Edited by Conner M, Norman P. Berkshire: Open University Press; 2005:276-323.

59. Sniehotta FF, Scholz U, Schwarzer R: Action plans and coping plans for physical exercise: a longitudinal intervention study in cardiac rehabilitation. Br J Heal Psychol 2006, 11(Pt 1):23-37.

60. Balmford J, Borland R, Burney S: The influence of having a quit date on prediction of smoking cessation outcome. Heal Educ Res 2010, 25(4):698-706.

61. Dijkstra A: Disengagement beliefs in smokers: do they influence the effects of a tailored persuasive message advocating smoking cessation? Psychol Heal 2009, 24(7):791-804.

62. Dijkstra A, De Vries H, Roijackers J: Computerized tailored feedback to change cognitive determinants of smoking: a Dutch field experiment. Heal Educ Res 1998, 13(2):197-206.

63. Gwaltney CJ, Metrik J, Kahler CW, Shiffman S: Self-efficacy and smoking cessation: a meta-analysis. Psychol Addict Behav 2009, 23(1):56-66.

64. Haug S, Meyer C, Ulbricht S, Schorr G, Ruge J, Rumpf HJ, et al: Predictors and moderators of outcome in different brief interventions for smoking cessation in general medical practice. Patient Educ Couns 2010, 78(1):57-64.

65. Elfeddali I, Bolman C, Candel MJ, Wiers RW, De Vries H: The role of selfefficacy, recovery self-efficacy, and preparatory planning in predicting short-term smoking relapse. Br J Heal Psychol 2012, 17(1):185-201.

66. West R: The multiple facets of cigarette addiction and what they mean for encouraging and helping smokers to stop. COPD 2009, 6(4):277-283.

67. Smit ES, Fidler JA, West R: The role of desire, duty and intention in predicting attempts to quit smoking. Addiction 2011, 106(4):844-851.

68. Verplanken B: Beyond frequency: habit as mental construct. $\mathrm{Br} J \mathrm{SoC}$ Psychol 2006, 45:639-656.

69. O'Connell KA, Hosein VL, Schwartz JE, Leibowitz RQ: How does coping help people resist lapses during smoking cessation? Heal Psychol 2007, 26(1):77-84.

70. Michie S, Churchill S, West R: Identifying evidence-based competences required to deliver behavioural support for smoking cessation. Ann Behav Med 2011, 41(1):59-70.

71. Mudde AN, de Vries $\mathrm{H}$ : The reach and effectiveness of a national mass media-led smoking cessation campaign in The Netherlands. Am J Public Health 1999, 89(3):346-350.

72. Bolman C, de Vries H, van Breukelen G: Evaluation of a nurse-managed minimal contact smoking cessation intervention for cardiac patients. Heal Educ Res 2002, 17:99-116.

73. Dijkstra A, Conijn B, de Vries H: A match-mismatch test of a stage model of behavior change in tobacco smoking. Addiction 2006, 101:1035-1043.

74. Zhou X, Nonnemaker J, Sherrill B, Gilsenan AW, Coste F, West R: Attempts to quit smoking and relapse: factors associated with success or failure from the ATTEMPT cohort study. Addict Behav 2009, 34(4):365-373.

75. Bandura A: Social Foundations of Thought and Action: A Social Cognitive Theory. Upper Saddle River, New Jersey, USA: Prentice-Hall; 1986.

76. Dholakia U, Bagozzi R: Mustering motivation to enact decisions: how decision process characteristics influence goal realization. J Behav Decis Mak 2002, 15(3):167-188.

77. Larabie L: To what extent do smokers plan quit attempts? Tob Control 2005, 14(6):425-428.

78. Murray RL, Lewis SA, Coleman T, Britton J, McNeill A: Unplanned attempts to quit smoking: missed opportunities for health promotion? Addiction 2009, 140(11):1901-1909.

79. Ferguson SG, Shiffman S, Gitchell JG, Sembower MA, West R: Unplanned Quit Attempts - Results from a US sample of smokers and ex-smokers. Nicotine Tob Res 2009, 11(7):827-832.

80. Cooper J, Borland R, Yong H-H, McNeill A, Murray RL, O'Connor RJ, Cummings KM: To what extent do smokers make spontaneous quit attempts and what are the implications of smoking cessation maintenance? Findings from the International Tobacco Control Four country survey. Nicotine Tob Res 2010, 12(1):S51-S57.

81. Prochaska JO: What do we know about unplanned quit attempts? Practically nothing or nothing practical? Addiction 2011, 106(11):2014-2015.

doi:10.1186/1471-2458-13-393

Cite this article as: de Vries et al.: The role of action planning and plan enactment for smoking cessation. BMC Public Health 2013 13:393. 